\title{
Market development for a construction and demolition waste stream in Australia
}

\author{
Salman Shooshtarian*iD, Tayyab Maqsood iD, Peter S.P. Wong (iD, Malik Khalfan iD, \\ Rebecca J. Yang iD \\ RMIT University, School of Property, Construction and Project Management, Melbourne, Australia
}

\begin{abstract}
In Australia, construction and demolition activities have substantially grown over recent decades leading to the generation of a large amount of waste. Among available options, the development of end markets for construction and demolition (C\&D) waste materials is regarded as a sustainable option to tackle issues around their management. Despite the promotion of a circular economy and the existence of some trading platforms set to facilitate $C \& D$ waste exchange in Australia, no research has been conducted to understand how various key stakeholders perceive their role in the $C \& D$ waste management system. Hence, this paper aims to identify the perceptions of key Australian C\&D waste stakeholders on the market development for recyclable materials. The study conducted a questionnaire survey in 2019 , aiming to capture the main C\&D waste stakeholders on market development. In total, 132 responses were collected, and the analytical results show that participants significantly support implementing more market incentives to reduce waste disposal. They also indicate that investment in technology and infrastructure, sustainable procurement and landfill levies are three major influential factors that have a significant impact on market development. The research findings can inform decisions and policies developed in Australia to establish end markets for C\&D waste management effectively.
\end{abstract}

\section{Keywords}

Circular economy; Recyclable C\&D waste materials; Landfill levy; Sustainable procurement; Technology and infrastructure

Received: 13 May 2020; Accepted: 24 September 2020

ISSN: 2630-5771 (online) C 2020 Golden Light Publishing All rights reserved.

\section{Introduction}

With rapid urbanisation around the world, construction activities continue to grow to an unprecedented extent. As a result, the construction industry currrently accounts for $35 \%$ of the total waste sent to landfill worldwide [1, 2]. For instance, in the UK, $49 \mathrm{Mt}$ of C\&D waste was generated in 2014; more than half of this amount was landfilled [3]. In China, the annual C\&D waste generation is
2.36 BT [2] and in the US, this figure was $516 \mathrm{Mt}$ in 2017 [4]. In Australia, construction and demolition activities have substantially grown over recent decades leading to the generation of a large amount of waste [5]. The C\&D waste stream, therefore, accounts for $43 \%$ of the total waste generated, reaching 20.4 Mt annually [6]. The average annual growth of $\mathrm{C} \& \mathrm{D}$ waste generation is currently at $2 \%$, and about $6.7 \mathrm{Mt}$ of this waste stream is landfilled [7]. The development of a

* Corresponding author

Email: Salman.shooshtarian@rmit.edu.au 
market for salvaged and recycled waste materials (including C\&D waste) has been advised as a sustainable solution to reduce waste disposal [8]. Hence, multiple pieces of literature, industry reports, policies, strategies and guidelines have emphasised the necessity of a marketplace in the management of C\&D waste [9-12].

Within the Australian context, the circular economy of waste has five principles, the third of which is to increase the use of recycled material and build demand and markets for recycled products'; that is, market development [13, 14]. In the Australian National Waste Policy [12], Strategy 14 places emphasis on market development and research. Estimations, based on the current solid waste generation rates in Australia, project that Australian recycling capacity must increase by $400 \%$ by 2040 to address the issue of solid waste in the future [15]. Furthermore, the influence of China's new waste policy and anti-waste movements in other countries, including Thailand, Malaysia and Philippines urgently necessitates the development of domestic market capacity in Australia [16, 17]. Several internal and external factors strongly influence the development of a domestic market for waste and recyclables. The following are a short review of factors identified to affect market development for C\&D waste materials:

National leadership - The Australian federal government is in the best position to respond to market developments by providing recycling regulations that align with the limited constitutional responsibilities of the federal government in the regulation of waste. Landfill levy-landfill levy is an effective pecuniary impost that if properly designed, can lead to further resource recovery [18] and market development [7]. Unreasonable (both high and low price signal) priced landfill fees and their variation can negatively hinder $C \& D$ waste market development [7, 19]. China's new waste policy - Australia exports recyclable material to over 100 countries, with 4.23 megatonnes of recycled materials exported in 2016-17 [20]. As discussed previously, the introduction of China's new policy (National Sword Policy) has a diverse impact on the performance of the market for C\&D waste. While it motivates the development of a market, it will have some negative impact on C\&D waste management since the local markets are not yet fully established.

Data and papering - Accurate C\&D waste data collection and papering underpin the development of a local market for recyclables. Consistent and updated papering can make it much easier to manage the $C \& D$ waste and resource market. Waste data is critical to well-targeted, evidence-based and planned waste projects and programs [21]. Data on waste generation, landfill and resource recovery is also essential to the development and implementation of waste policies and programs. Research and development- Any integrated waste management system greatly benefits from research and development [22]. Almost every single strategy, policy, action plan and regulation on waste management in Australia has highlighted the role of R\&D alongside with encouragement and enforcement for effective development and implementation of waste-related plans such as market development [9]. Waste management schemes- product stewardship, extended producer responsibility [23] and take-back schemes are strong motivators for the establishment of a market. It is recommended that these schemes be regulated and implemented nationally because many of the potential participants work across Australian jurisdictions [15].

Regulatory support- It is vital that waste regulatory frameworks are set to be in favour of local market development and implementation of an effective circular economy. The issues that must be addressed in this regard are inconsistency in jurisdictional waste regulations throughout Australia, clarification on the waste definition including when waste becomes a resource and is not liable for landfill levy, weak or inconsistent regulations that encourages illegal dumping and stockpiling activities and inconsistent reporting obligations. Geographical location and population density-Australia is a vast country with a relatively low population. The population is concentrated in capital cities, which challenges market 
development. As a result, long distances between waste origins, waste facilities and the place that receives recycled and salvaged $C \& D$ waste are regarded as a barrier to the development of a domestic market. Supply chain- Providing an efficient and effective supply chain to the waste and resource recovery industry is instrumental in developing a local market for $C \& D$ waste [10]. The supply chain for this purpose needs to consider the principles of the circular economy and be driven by the industrial ecology (symbiosis) concept (The wastes or by-products of one industry are used as inputs in another industry, thereby closing the material loop of industrial systems and minimising waste).

Sustainable procurement (SP)- This can provide an incentive for further waste recovery. It is claimed that the implementation of SP has a spreadsheets impact on the flourishing of the C\&D waste material market. Green construction- Green construction has proven to hold a critical role in boosting C\&D waste market worldwide [24], notably when it is implemented obligatorily and is a requirement for large-scale or government projects. In Australia, there are two voluntary industry-based rating systems, namely the 'Green Star' (GS) program and 'Sustainability Infrastructure' (SI), which promote the concept of green construction [24]. Investments in technology and infrastructure- Advances in waste recovery technology and infrastructure are advantageous to domestic market development. Building modern and efficient facilities not only addresses public social and environmental concerns but also provides better services to the waste and resource recovery industry through economies of scale. Employment- The potential for jobs to be created through a local market is attractive to decisionmakers, politicians and different stakeholders [25, 26]. The extent to which waste recovery activities can give rise to employment can be assumed to be proportional to the level of support provided by officials in government departments that consist of politicians from major parties in Australia [27].

\subsection{C\&D waste trading platforms in Australia}

The first online marketplace for C\&D waste materials trading platform, called Yours2Take, was created in 2008 and aimed to provide a means like eBay for waste traders. However, this platform ceased to operate in 2016 for some unknown reasons. Afterwards, two other platforms called Waste Choices and RecycleBuild were developed between 2011 and 2014, which discontinued in 2016 and 2018, respectively. Currently, there are three active platforms that facilitate $C \& D$ waste materials; these include ASPIRE, Buy Recycled and Business Recycling. The latter two platforms are supported by the Victorian and NSW governments. Table 1 summarises the operational model of these platforms.

\section{2. $C \& D$ waste trading platforms overseas}

The four top countries in the development of a marketplace for waste trading are the US, France, the UK and Canada. According to statistics collected by an online tool called MarketplaceHUB (https://marketplacehub.org), a network of circular economy practitioners, the US, with more than 25 major marketplaces across its states, is the leading country in following circular economy principles and increasing waste diversion to landfills [17]. The top materials being traded across the marketplaces, described in Table 2, are metal and alloys. C\&D waste holds the sixth position after plastic and polymers, biotic resources, E-waste and other categories. According to the data collected from 108 marketplaces operating in various geographical locations around the world [17], the four main sources of income for marketplaces are 'advertising', 'funding', 'membership' and 'public finance'.

Despite the existence of some trading platforms set to facilitate C\&D waste exchange in Australia (Table 1), no research has been conducted to understand how various key stakeholders perceive their role in the C\&D waste management system. Hence, this paper aims to identify the perceptions of Australian key C\&D waste stakeholders on the market development for recyclable materials. 
Table 1. Online market for C\&D waste trading in Australia

Platform name
Buy Recycled
(https://directories.sustainability.vic
.gov.au/buy-recycled)

\section{Business Recycling}

(https://businessrecycling.com.au)

\section{ASPIRE \\ (https://aspire.csiro.au)}

\section{GreenHands}

(https://www.greenhands.net.au)

Yours2Take

\section{Waste Choices}

\section{RecycleBuild}

(http://www.recyclebuild.com.au)
Operational model

In 2020, Sustainability Victoria launched an online directory that will feature local, Victorian products containing recycled content. The directory will help the Victorian government source recycled materials. It will be used by state and local government procurers and buyers to help them easily research, review, and access recycled content products.

In partnership with the NSW Government (Department of Planning, Industry and Environment), Plant Ark launched Australia's most comprehensive online database that helps small to medium businesses find recycling collection and support services for the workplace. This platform, which was founded in 2019, invites providers of recycling and waste disposal services to list their details for free.

Advisory System for Processing, Innovation and Resource Exchange (ASPIRE) is an online marketplace that intelligently matches businesses with potential purchasers or recyclers of waste by-products. ASPIRE was developed by The Commonwealth Scientific and Industrial Research Organisation (CSIRO) in partnership with several Victorian councils; its operation officially commenced as of 2018. This system requires patrons to enter details about the type and quantity of their exchangeable inputs and waste materials (outputs). Using this data, ASPIRE's Supply Chain Options Model determines optimal sources and destinations for the materials, including options for aggregation with other local businesses, appropriate investment opportunities such as compactors for low-density wastes, and local recyclers. ASPIRE is deployed using existing established council and manufacturing business networks and supports local government business sustainability programs.

Greenhands is a free online marketplace for recyclable excavated resources, C\&D waste materials and salvaged goods. It includes a directory of resource/waste facilities, building contractors, construction sites, transporters, skip bins, rubbish removal and plant hire. Builders use GreenHands to source and dispose materials for projects; it can connect users with builders nearby to trade their excess or recycled materials with them.

This online platform was an initiative of the Riverina Eastern Regional Organisation of Councils (REROC), implemented in 2008 through its waste forum, which was officially closed in 2016. REROC was a voluntary strategic alliance of 15 councils located in the eastern Riverina region of New South Wales (NSW). Y2T utilised a platform like eBay to allow users to upload items that they want to give away and acquire items that they want to procure.

This platform was launched in 2014 and later discontinued in 2016. The platform was set upto improve waste management and resource recovery activities and to help businesses that wanted a simple, fast, transparent, cost-effective and compliant solution for waste collection, recycling, treatment and disposal. Through this platform, businesses of any size had the flexibility of posting a one-off project or an ongoing contract for the management of over 30 waste streams. The service seekers could select from a range of competitive bids from 14 national and state-based waste management providers with the flexibility to award a project based on the price or reputation of the provider.

This website provides an online platform for trading building materials across Australia under three main categories of new, used and unused. The RecycleBuild is a company based in Queensland that manages this online marketplace and provides an opportunity for sellers to advertise their waste for free if they are public or give away their materials. Construction companies and other businesses also can benefit from discounted fees for bulk advertisement. This company sells credit for advertisement and does not charge a commission fee to their account holders. 
Table 1. International online trading platforms for C\&D waste

\begin{tabular}{lll}
\hline Platform name & Location & Operational model \\
\hline $\begin{array}{l}\text { 2Good2Waste } \\
\text { (https://2good2waste.com) }\end{array}$ & US & $\begin{array}{l}\text { This platform provides the opportunity to trade waste across selected } \\
\text { states. It facilitates resource rocovery and promotes an important } \\
\text { environmental ethic. The platforms run in three simple steps of finding } \\
\text { materials, posting materials and making exchange. }\end{array}$
\end{tabular}

Materials Marketplace

US

(https://go.materialsmarketplace.org)

MarketplaceHub International

(https://marketplacehub.org)

\section{Salza}

(https://www.salza.ch)

Backacia

(https://www.backacia.com)

Austin Materials Marketplace

(http://austintexas.gov/zerowaste)
This national and global platform is developed by the US Business Council for Sustainable Development to facilitate company-tocompany industrial reuse. Through a cloud-based platform, this marketplace matches traditional and non-traditional industrial waste streams leading to a cultural shift to a circular, closed-loop economy. It provides an efficient user experience as well as the ability to capture and leverage data to produce actionable insights about materials and their potential uses. The marketplace actively analyses available materials and sends its members curated matches. Currently, more than 2,000 businesses and organisations are registered on this platform. The Ohio division of this platform diverted about 1,525 tonnes and creates $\$ 150 \mathrm{k}$ in disposal savings and value creation in the first year. The platform has extended its services to a few other countries, namely Turkey, Vietnam, and Israel.

International The MarketplaceHub is a tool designed to foster sustainable use of resources through accelerating business-to-business reuse opportunities for secondary materials worldwide. It has developed a map that gives an overview of 108 existing materials marketplaces and industrial synergy networks around the world, searchable by materials or location [17]. At the moment, 39 marketplaces can handle C\&D waste materials. This online tool also regularly conducts market study and analysis to identify the main challenges to the sustainable operation of waste marketplaces.

Switzerland Salza is an online marketplace that was found in Switzerland. It aims to boost the current practice of reuse in Switzerland. On this platform, owners can notify others about a building that is meant to be demolished or renovated. This allows architects, designers, and artists to discover valuable elements that could be reused in a new project. Salza puts the owner and customers in direct contact.

France Backacia is an online start-up that specialises in the reuse of building components. This marketplace was launched in France in 2017. The products on sale on the marketplace are either from surplus orders or deconstructed buildings of professional quality.

The City of Austin was the first to implement a Zero Waste Plan in 2009, a strategy aiming at improving waste management to "reach the City Council's goal of Zero waste by 2040? In 2011, the City adopted the Austin Resource Recovery Master Plan in an attempt to accelerate the implementation of the Zero Waste Strategic Plan. The aim was to increase waste diversion to $90 \%$ by 2045 . In its recommendations, the City planned to "expand and improve local and regional reuse, recycling and composting programs" as well as "involve the community through collaboration and partnerships to achieve Zero Waste" ${ }^{9}$. It is in this context that the Austin materials marketplace was launched in 2013, considered a tool to foster the implementation of the Strategic Plan. Being considered as an instrument to accelerate the application of the Waste Management Plan, the Austin Materials Marketplace was fully funded by the City of Austin. By contracting the management and operations of the marketplace to the US Business Council for Sustainable Development, the City recognised that success depended on external subject matter experts. 
Table 2. Cont'd

National Industrial Symbiosis Program

(http://www.nispnetwork.com)

Mjunction

India

(https://www.mjunction.in)

SMILE

Ireland

(http://smileexchange.ie)
NSIP was designed by International Synergies Ltd and launched in 2003 to address the challenges concerned with a knowledge gap in cross-sector second-hand material transaction. International Synergies aims to operationalise industrial symbiosis (the circular economy in action) methodology, tools and techniques. It has gained the attention of international organisations, governments and academia. This program produced a resource reuse database and management system (SYNERGie ${ }^{\circledR}$ ). This software facilitates resource matching for users using an extensive library of experience; it allows companies to identify reuse opportunities and minimise their waste.

Mjunction, a joint venture established by Steel Authority of India Limited (SAIL) and TATA Steel in 2001, is currently the largest ecommerce platform for primary and secondary steel in the world. Initially focused on steel, Mjunction rapidly expanded to new business lines and now offers e-Finance, e-Selling, e-Sourcing and e-Knowledge services for various goods such as steel, and coal. The success of this marketplace can be partly linked to its e-Sales process. Their e-auction service ensures buyers and sellers "transparent pricing based on the market situation". This system, in addition to providing information regarding the availability and quality of materials, allows both parties to benefit from a trusted environment and pursue their exchange safely. The forward auction system awards the highest bidder of the material. In this process, buyers and sellers can see the price and the number of parties involved in the exchange at any time. They also can be assisted by "tele-executives" during the process.

SMILE (Saving Money Through Industry Links \& Exchanges), founded in 2010 and discontinued in 2018, was a resource exchange platform embedded in Ireland's National Program for industrial synergies. The program drew on industrial symbiosis and focused on improving companies abilities in reusing second-hand materials. The process in this platform started with the identification of synergies through the free online platform; then members would benefit from the technical support in completing the transaction. Delivered by consultants based in each of the three waste regions across the country, this service facilitated the exchange by providing materials reprocessing expertise. The other services provided by this platform included sending consultants to visit companies and offering them personalised feedback regarding their exchange opportunities. The support team also facilitated the negotiations between parties to assist with removing the challenges that typically appear when trading secondary materials. Besides, the program provided opportunities for companies to find their potential partners by holding networking events throughout a year. Using this platform, companies could acquire secondary materials at competitive prices. Often, businesses saved costs associated with landfilling too.
This study is part of a larger national study (Project 1.65. A National Economic Approach to Improved Management of Construction and Demolition Waste) that investigated the harmonisation of $C \& D$ waste management systems in Australia. The study was funded by the Australia Sustainable Built Environment National Research Centre (20182020). The study objectives were:
- to explore the level of agreement with market incentives approach in Australian C\&D waste management system; and

- to identify the most important strategies aiding the development of a national C\&D waste market. 


\section{Methodology}

\subsection{Data collection}

A questionnaire survey was performed to achieve the main aim of this research. Qualtrics, an online survey toolkit, was used to design the questionnaire [28] and to circulate it among the participants. The questionnaire was reviewed and refined by Australian waste management and construction industry experts. The conduction of the survey was approved by the RMIT University Human Ethics Committee, College Human Ethics Advisory Network (CHEAN) (CHEAN A\&B 21847-11/18). The questionnaire contained 46 questions about various aspects of $C \& D$ waste management in Australia. However, using the logical skip function in Qualtrics, some questions only appeared to a specific group of respondents, making the number of questions to be answered fewer. The online questionnaire consisted of 11 question packages with each package being intended for the investigation of a particular C\&D waste management dimension. The question packages targeted participant demographic details, general overview of $C \& D$ waste management issues, levy imposition, $C \& D$ waste regulation, the impact of (and response to) China's new waste policy, wasterelated advisory/mandatory schemes, C\&D waste management practice in construction firms, $C \& D$ waste material recycling in recycling facilities, C\&D waste and construction material manufacturers, $C \& D$ waste and delivery and transport, and establishment of C\&D waste marketplace. For this study, only responses from two packages (i.e. participants' demographic details and establishment of C\&D waste marketplace), were selected and analysed. In total, these two packages consisted of five questions that were designed to elicit the most relevant information about C\&D waste market development. The questions on participants' demographic details sought the participants' field of activity, experience and the primary location of their activity, while other questions focused on participants' agreement and opinion on $C \& D$ waste marketplace.

\subsection{Data analysis}

After screening the survey responses, the selected data was analysed using descriptive analysis. In total, 132 participants took part in this online survey. Frequency distribution was the main statistical measure to compare different categories of responses received from participants. Excel Spreadsheet v. 2016 was used to archive, screen, and analyse the data collected.

\section{Results}

\subsection{Participants profile}

To better understand and analyse the responses received from the participants, three questions were formulated to seek participants' demographic data, including the industry and geographical zone in which they perform their main activities and their length of experience. More than $50 \%$ of the participants belonged to three sectors: waste recovery (20\%), construction (16\%) and landfilling $(15 \%)$. In terms of their length of experience working in C\&D waste space, as shown in Table 3, about $44 \%$ of participants had fewer than six years, and fewer than $30 \%$ of them had worked in an industry related to $\mathrm{C} \& \mathrm{D}$ waste management for more than 15 years at the time of running the survey. More than $60 \%$ of participants were based in the two large states of Victoria and NSW (Table $3)$.

\subsection{Market incentives to reduce waste disposal}

Participants were asked to express the level of their agreement with having more market incentives for C\&D waste management. The question posed was: Express your degree of agreement on the following statements: - More market incentives (e.g. remove regulatory barriers; foster minimum recycled content in products; invest in technologies to recycle and facilitate trade such as trading platforms) can better increase $C \& D$ waste reduction, reuse and recycling in Australia. For the first category, the responses showed that the respondents significantly favoured market incentives (Fig. 1), with more than 92\% level of agreement and somewhat agreement. 
Table 2. Study participants' profile.

\begin{tabular}{|c|c|c|}
\hline Question & Distribution & $(\%)$ \\
\hline \multirow[t]{11}{*}{ Field of activity } & Construction & 16 \\
\hline & Demolition & 8 \\
\hline & Landfill & 15 \\
\hline & Legislation & 6 \\
\hline & Industry association & 6 \\
\hline & Waste recovery & 20 \\
\hline & Waste delivery and transport & 10 \\
\hline & Consultancy & 7 \\
\hline & Manufacturing & 4 \\
\hline & $R \& D$ & 3 \\
\hline & EPA enforcement & 5 \\
\hline \multirow[t]{4}{*}{ Experience } & $<6$ years & 43.1 \\
\hline & $6-10$ years & 13.7 \\
\hline & $11-15$ years & 16.7 \\
\hline & $>15$ years & 26.5 \\
\hline \multirow[t]{7}{*}{ State/territory } & Australian Capital Territory (ACT) & 1.8 \\
\hline & New South Wales (NSW) & 24.3 \\
\hline & Northern Territory (NT) & 6.4 \\
\hline & Queensland (Qld) & 16.2 \\
\hline & Tasmania (Tas) & 3.6 \\
\hline & Victoria (Vic) & 30.6 \\
\hline & Western Australia (WA) & 17.1 \\
\hline
\end{tabular}

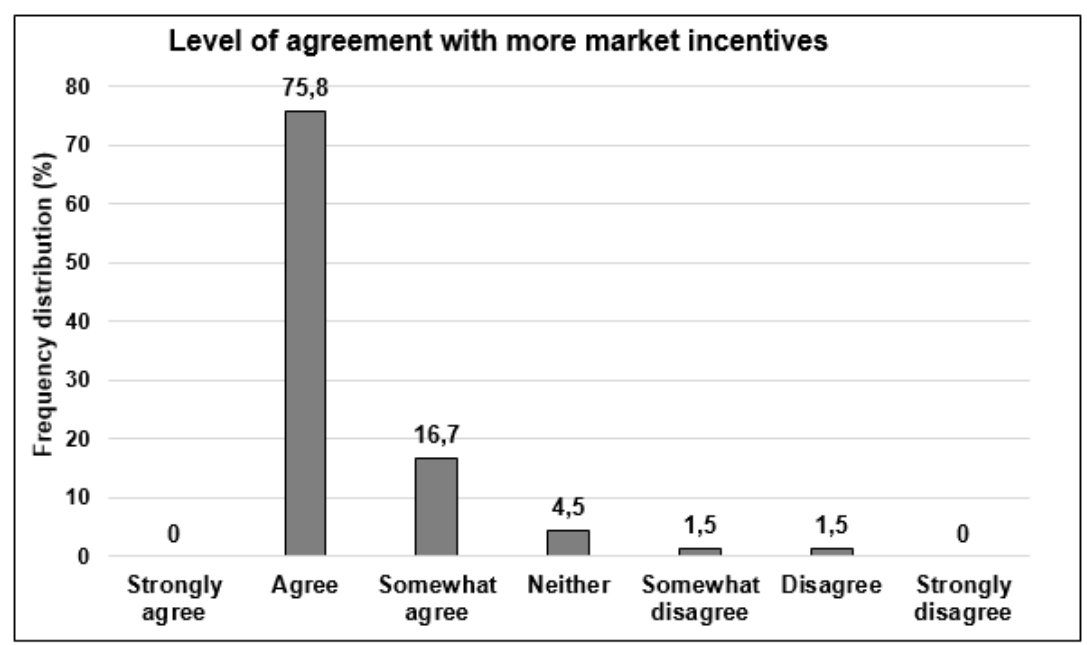

Fig. 1. Frequency distribution of agreement level with the increased implementation of market incentives. 


\subsection{Factors impacting the development of $C \& D$ waste market}

Development of a domestic market for recyclables is a sustainable method within the circular economy context [10]. However, as noted, the development of such a market needs to be done carefully. Various factors can impact market development negatively or otherwise. The choices included 'investment in technology and infrastructure', 'virgin material tax', 'product stewardship', 'employment', 'sustainable procurement', 'adequate supply chain system', 'penalty for illegal dumping', 'sustainability rating schemes (i.e. GS and SI)', 'national approach', 'landfill levy', and 'waste data collection \& reporting'. As depicted in Fig. 2, respondents indicated that 'investment in technology and infrastructure' (16.7\%), 'sustainable procurement' (14.6\%) and 'landfill levy' $(13.2 \%)$ are three major influential factors that have a significant impact on market development.

\section{Discussion}

\subsection{Primary strategies to develop and stimulate markets}

The results of the survey targeting key C\&D waste management stakeholders showed that they significantly agree with more market incentives and indicated that investment in technology and infrastructure, sustainable procurement and landfill levies are three major influential factors that have a significant impact on market development and operation. Technically, several waste minimisation practices and strategies, such as extended producer responsibility, depend on the availability of technologically advanced local infrastructures. The use of new technologies, such as Building Information Modelling (BIM), Geographical Information Systems (GIS) and the blockchain can solve several issues towards the successful operation of a market for recyclable $C \& D$ waste materials.

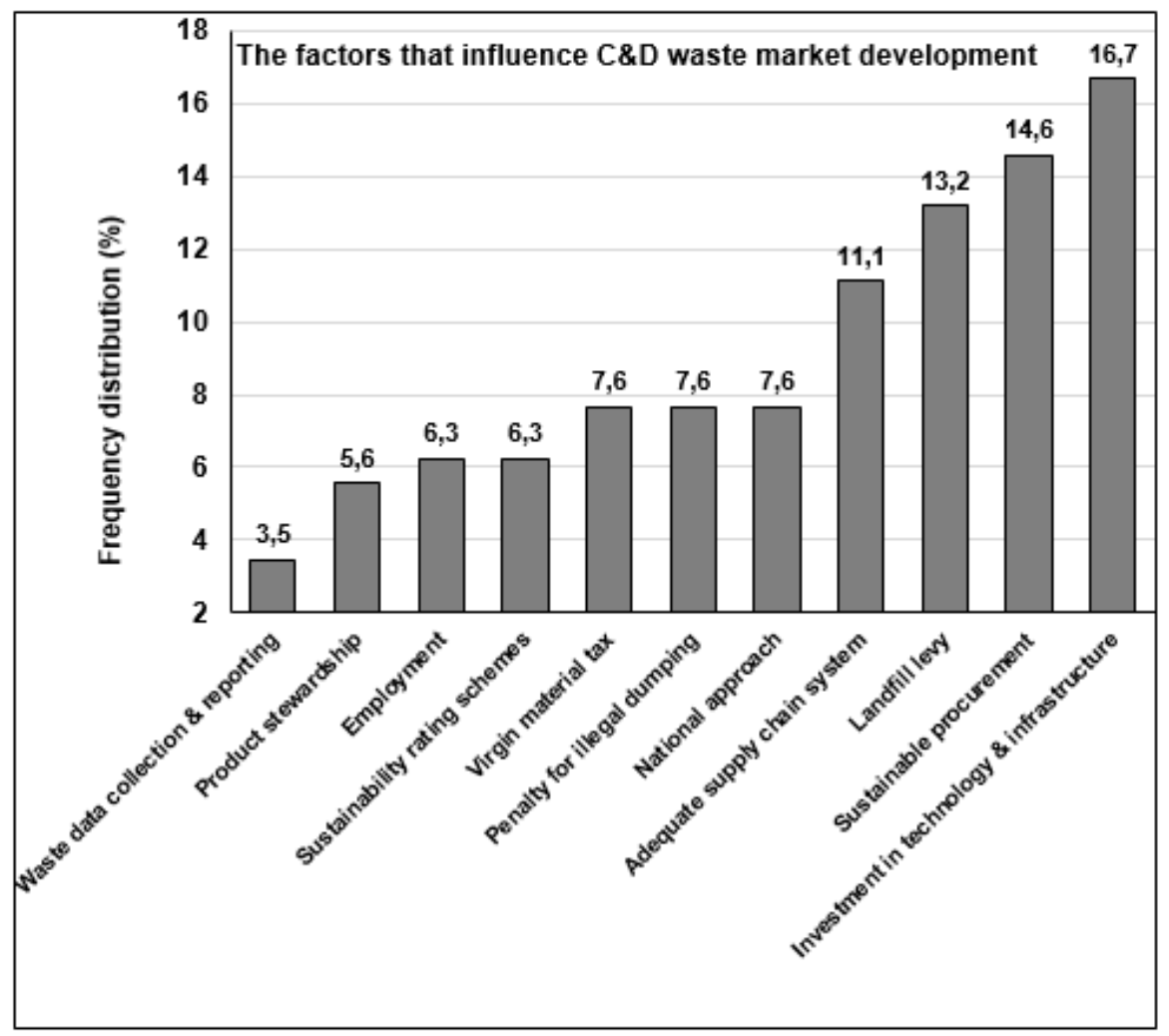

Fig. 2. Participants' selection of factors that influence the establishment of C\&D waste market. 
The Australasian Procurement and Construction Council Australian and New Zealand Government Framework for Sustainable Procurement is implemented by the federal government to pursue three aims when procuring goods, services, works and utilities. These aims involve the reduction of environmental impacts, social impact and economic impacts through the procurement process. This framework also shares some premises with the circular economy in considering alternatives to the 'take, make and dispose of' approach. According to this framework, the government has a decisive role in providing a market driver for increased use of recycled materials in the goods and works that it procures. Therefore, the federal government and some state governments developed SP guidelines to coordinate their decisions and actions towards SP and the purchasing of recycled materials. In 2012, the state government of SA was the first authority to release a Sustainable Procurement Guide. One year later, in 2013, the federal government also released the first Australian guideline on SP. This work was further complemented by state-specific guidelines to tailor sustainable procurement requirements in the ACT (2015), NSW (2017) and WA (2017).

There are multiple other sources that necessitate having a landfill levy in place in regard to market development [7]. For instance, several submissions to Environment and Communications References Committee [15] indicated that levy revenue could be used to invest in the development of a market for recycled materials through low-interest (subsidised business) loans or financial incentives and R\&D. The National Waste and Recycling Industry Council firmly believes that market distortions take place due to variation in landfill levies across jurisdictions [15].

\subsection{Policy development}

The results of the study contribute to policy development activities across the Australian states and territories. Notably, those public agencies that are responsible for strategising market development can benefit from the input provided by participants about the main priorities and key improvement areas that affect market development and stimulation. At the time of writing this paper, several public agencies such as Green Industries (SA) and Waste Authority (WA) have released consultation papers to obtain expert and public opinions about waste management priorities and action plans. The submissions are supposed to be adopted for and inform policy development in the given states and territories.

\section{Conclusion}

This study surveyed 132 Australian key C\&D waste stakeholders regarding their perceptions on the market development for recyclable materials. Sustainable procurement, the imposition of landfill levies and investment in technology and infrastructure were identified as the main drivers for the creation and stimulation of markets for recycled materials. Further research is required to understand how the application of these strategies can be optimised and to ensure that the desired outcomes will be achieved. Furthermore, the disproportional frequency of responses from various stakeholders made it difficult to infer a meaningful relationship between participants' profile (location, experience and activities) and their responses to questions related to market development. It is recommended that further studies focus on identifying the interaction between these factors. Lastly, it is suggested that future studies investigate the performance of existing marketplaces operating across Australia to find opportunities for further improvements. The study results could be used by policymakers and decision-makers to develop policies that will facilitate effective management of C\&D waste stream in Australia.

\section{Declaration of conflicting interests}

The author(s) declared no potential conflicts of interest with respect to the research, authorship, and/or publication of this article.

\section{Acknowledgements}

The research team would like to acknowledge the support of the Australia Sustainable Built 
Environment National Research Centre (SBEnrc), Project 1.65. However, the views expressed in this paper are those of the authors and do not necessarily represent the views of SBEnrc. Furthermore, the authors appreciate the Waste Management and Resource Recovery Association of Australia for assisting with the circulation of the study's survey.

\section{References}

[1] Solís-Guzmán J, Marrero M, Montes-Delgado MV, Ramírez-de-Arellano A (2009) A Spanish model for quantification and management of construction waste. Waste Management 29(9):2542-8.

[2] Zheng L, Wu H, Zhang H, Duan H, Wang J, Jiang $\mathrm{W}$, et al. 2017) Characterizing the generation and flows of construction and demolition waste in China. Construction and Building Materials 136:405-13.

[3] Menegaki M, Damigos D (2018) A review on current situation and challenges of construction and demolition waste management. Current Opinion in Green and Sustainable Chemistry 13:8-15.

[4] US EPA. Advancing sustainable materials management: 2017 Fact sheet. EPA 530-F-19-007. United States Environmental Protection Agency; 2019.

[5] Shooshtarian S, Maqsood T, Khalfan M, Wong SP, Yang JR. Managing construction and demolition (C\&D) waste in Australia. CIB World Building Congress 2019 'Constructing Smart Cities'; 17-21 June Hong Kong, China: Faculty of Construction and Environment, The Hong Kong Polytechniques University; 2019.

[6] Shooshtarian S, Maqsood T, Wong P, Khalfan M, Yang R (2019) Review of energy recovery from construction and demolition waste in Australia. Journal of Construction Engineering, Management \& Innovation 2(3):112-30.

[7] Shooshtarian S, Maqsood T, Khalfan M, Yang JR, Wong SPP (2020) Landfill levy imposition on construction and demolition waste: Australian stakeholders' perceptions Sustainability 12(11):115.

[8] Sustainability Victoria. Victorian Market Development Strategy for Recovered Resources. Melbourne, Australia 2016.

[9] Shooshtarian S, Maqsood T, Wong SP, Yang JR, Khalfan M (2020) Review of waste strategy documents in Australia: Analysis of strategies for construction and demolition waste. International
Journal of Environmental Technology and Management 23(1):1-21.

[10] Shooshtarian S, Maqsood T, Wong SPP, Khalfan M, Yang RJ. Development of a domestic market for construction and demolition waste in Australia. 43rd AUBEA Conference: Built to Thrive: Creating Buildings and Cities That Support Individual Well-Being and Community Prosperity; Noosa, Australia: CQ University; 2019.

[11] Caldera S, Ryley T, Zatyko N, editors. Developing a marketplace for construction and demolition waste. 1st Asia Pacific SDEWES Conference: Engineering a Sustainable Circular Economy: Materials, Energy and Infrastructure Integration for Smart Cities and Industry; 2020 6-9 April Gold Coast, Australia.

[12] National Waste Policy. Less Waste. More Resources. 2018.

[13] Perey R, Benn S, Agarwal R, Edwards M (2018) The place of waste: Changing business value for the circular economy. Business Strategy and the Environment 27(5):631-42.

[14] Florin N, Madden B, Sharpe S, Benn S, Agarwal R, Perey R, et al. Shifting Business Models for a Circular Economy: Metals Management for MultiProduct-Use Cycles. UTS: Sydney, Australia. 2015.

[15] Environment and Communications References Committee. Never waste a crisis: the waste and recycling industry in Australia. Canberra, Australia Parliament of Australia 2018.

[16] Shooshtarian S, Khalfan M, Maqsood T, Wong S.P. P, Yang JR (2020) The Australian Construction and Demolition Waste Management in the Face of New Waste Import Policies by Foreign Countries International Journal of Environmental Technology and Management (under review).

[17] A network of circular economy practitioners [Internet]. 2020. Available from: https://marketplacehub.org/.

[18] Yu ATW, Poon CS, Wong A, Yip R, Jaillon L (2013) Impact of Construction Waste Disposal Charging Scheme on work practices at construction sites in Hong Kong. Waste Management. 33(1):138-46.

[19] Arslan V, Ulubeyli S (2019) Sorting at source and reusing: The case of construction and demolition waste in Turkey. Journal of Construction Engineering, Management \& Innovation 2(4):2306. 
[20] Blue Environment. Data on exports of recyclables from Australia to China. 2018.

[21] Net Balance. National Waste Data System Requirements Study. Department of the Environment, Water, Heritage and the Arts; 2009.

[22] Gálvez-Martos J-L, Styles D, Schoenberger H, Zeschmar-Lahl B (2018) Construction and demolition waste best management practice in Europe. Resources, Conservation and Recycling 136:166-78.

[23] Shooshtarian S, Khalfan M, Wong PS, Yang RJ, Maqsood T. We create 20m tons of construction industry waste each year. Here's how to stop it going to landfill. The Conversation 2019.

[24] Shooshtarian S, Maqsood T, Peter SW, Malik K, Rebecca Y. Green construction and construction and demolition waste management in Australia. 43rd AUBEA Conference: Built to Thrive: Creating Buildings and Cities That Support Individual Well-Being and Community Prosperity; Noosa, Australia: CQ University; 2019.

[25] Yuan H 82013) Key indicators for assessing the effectiveness of waste management in construction projects. Ecological Indicators 24:476-84.

[26] Davis G (2013) Counting (green) jobs in Queensland's waste and recycling sector. Waste Management \& Research 31(9):902-9.

[27] Jones S (2019) Establishing political priority for regulatory interventions in waste management in Australia. Australian Journal of Political Science 117.

[28] Qualtrics L. Qualtrics [software]. Utah, USA: Qualtrics. 2014. 